\title{
Effect of Non-Steroidal Anti-Inflammatory Drug Mouthwash on Post-Tonsillectomy Pain: Randomized, Controlled Study
}

\author{
Kyung Yun Kang, Seung Jae Lee, Eunsang Lee, Jeong Yeop Lee, Ji Ho Choi, and Jae Yong Lee \\ Department of Otorhinolaryngology-Head and Neck Surgery, Soonchunhyang University College of Medicine, Bucheon Hospital, \\ Bucheon, Korea
}

\section{편도적출술 후 통증에 대한 비스테로이드성 항염증제 가글의 효과: 무작위 대조군 연구}

강경윤 · 이승재 · 이은상 · 이정엽 · 최지호 · 이재용

순천향대학교 의과대학 이비인후-두경부외과학교실

\author{
Received December 21, 2016 \\ Revised May 30, 2017 \\ Accepted June 14, 2017 \\ Address for correspondence \\ Jae Yong Lee, MD, PhD \\ Department of Otorhinolaryngology- \\ Head and Neck Surgery, \\ Soonchunhyang University \\ College of Medicine, \\ Bucheon Hospital, \\ 170 Jomaru-ro, Bucheon 14584, \\ Korea \\ Tel $+82-32-621-5448$ \\ Fax $+82-32-621-5016$
}

E-mail jyent@schmc.ac.kr
Background and Objectives Altough tonsillectomy is one of the most common otolaryngological procedures, a highly reliable and effective method for reducing postoperative pain has yet to be identified. This study evaluated the efficacy of a non-steroidal anti-inflammatory drug (NSAID) mouthwash on postoperative pain in tonsillectomy patients.

Subjects and Method A total of 64 patients who underwent tonsillectomy were randomly assigned to one of two groups (32 patients each). One group received the NSAID mouthwash and the other a distilled water mouthwash. Postoperative pain in the two groups was compared by assessing pain severity 1-9 days postoperatively using a visual analog scale.

Results Compared to the distilled water mouthwash group, patients using the NSAID mouthwash showed a statistically significant decrease in postoperative pain over the first 9 postoperative days.

Conclusion A NSAID mouthwash may be a simple and effective method for controlling posttonsillectomy pain when administered in conjunction with routine medications.

Korean J Otorhinolaryngol-Head Neck Surg 2017;60(10):512-6

Key Words Mouthwashes · Non-steroidal anti-inflammatory agents · Postoperative pain · Tonsillectomy.

\section{Introduction}

Tonsillectomy is one of the most common otolaryngological operations. It is performed for several conditions, including sleep disorders (e.g., snoring or apnea), recurrent tonsillitis, complications such as peritonsillar abscess, and tumors suspected to be malignant. ${ }^{1-3)}$ However, postoperative pain after tonsillectomy may be severe enough to impede a patient's

This is an Open Access article distributed under the terms of the Creative Commons Attribution Non-Commercial License (http://creativecommons.org/licenses/by-nc/4.0) which permits unrestricted non-commercial use, distribution, and reproduction in any medium, provided the original work is properly cited. normal academic or working activities and compromise his or her nutritional status. Among the methods proposed to reduce postoperative pain are various forms of surgery using different types of equipment, local anesthesia before surgery, steroids, antibiotics, analgesics, and cold-water cooling. ${ }^{4-9)}$ Nonetheless, a highly reliable and effective method for reducing postoperative pain has yet to be identified.

A non-steroidal anti-inflammatory drug (NSAID) mouthwash has been used in dentistry to reduce pain following periodontal surgery or pain caused by periodontitis, ${ }^{10)}$ but it has been rarely used in otolaryngological procedures. Thus, we 
conducted a randomized, controlled study to evaluate the efficacy of NSAID mouthwash in reducing post-tonsillectomy pain.

\section{Subjects and Method}

The patients enrolled in this study were 15 years of age or older and underwent a tonsillectomy between January and November 2016 at Soonchunhyang University Bucheon Hospital. The indication for surgery was recurrent or chronic tonsillitis. Patients who underwent additional procedures such as uvulopharyngopalatoplasty, those with significant medical morbidities or an active tonsillar infection, patients who declined to participate, and those who did not complete the questionnaire were excluded from the study. Informed consent was obtained from all participants. This study was approved by the Institutional Review Board of Soonchunhyang University (IRB No. 2016-014).

The demographics of the 64 patients who were included in the study are listed in Table 1 . This study was performed as single-blind, and the patients were randomly assigned to experimental (NSAID) and control (distilled water) groups $(\mathrm{n}=$ 32 patients per each). Randomization was performed according to the randomized list, which was constructed using a computer-generated randomization sequence. All surgical procedures were performed by the same surgeon (J.Y.L.) with the same methods under general anesthesia. After adequate exposure of the oral cavity with a McIvor tongue retractor, each tonsil was dissected in the extracapsular plane using monopolar electrocautery with a coagulation mode of $20 \mathrm{~W}$. Hemostasis was achieved by minimal spot electrocautery using bipolar forceps.

All patients were blinded as to whether they received NSAID (Diclomed $^{\circledR}, 0.074 \%$ solution; Valeas S.P.A. Industria Chim- ica E Farmaceutici, Milano, Italy) or distilled water mouthwash postoperatively. Distilled water mouthwash was manufactured under the consultation with nutrition and pharmacy departments. It had similar color with NSAID mouthwash, but did not contain any harmful or pharmacological properties. The patients in both groups rinsed their mouth with 15 $\mathrm{mL}$ of the respective mouthwash twice a day for $30 \mathrm{sec}$ each time, morning and evening, for 9 days after the operation. All of the patients were instructed to allow the solution to reach the tonsillar fossa. When they had difficulties in rinsing the tonsillar fossa, a spray bottle was provided.

After the operation, intravenous analgesics were administered to all patients $(75 \mathrm{mg}$ of diclofenac sodium mixed with $100 \mathrm{~mL}$ of $0.9 \%$ normal saline) at a dose interval of $8 \mathrm{~h}$; oral analgesics were administered once every $8 \mathrm{~h}$. Patients with unusually severe pain were administered additional diclofenac sodium via an intramuscular injection once or twice during their hospital stay. Patients in both groups were instructed to frequently rinse their mouth with ice water and $30 \times$ -diluted Povidone iodide ${ }^{\circledR}$ (7.5\%; Firson Co., Ltd., Cheonan, Korea) mouthwash. Most of the patients were discharged on the first postoperative day (POD); the average hospital stay was 1.3 days. Upon discharge, all patients were prescribed a 1-week course of oral antibiotics, analgesics (acetaminophen and trimadole, 3 time s a day), and either the NSAID mouthwash or distilled water mouthwash. They were also instructed to take oral acetaminophen if they experienced severe pain, even while taking the prescribed analgesics. Postoperatively, the patients received a questionnaire and were asked to record their subjective pain level on PODs 1-9 using a visual analog scale (VAS). A score of 0 indicated no pain or disturbances and a score of 10 unbearable pain. They were instructed to check the pain level in the morning 30 min after using

Table 1. Demographics and variables of the patients

\begin{tabular}{|c|c|c|c|c|}
\hline Variables & NSAID $(n=32)$ & DW $(n=32)$ & Total $(n=64)$ & $p$ value \\
\hline Average age (year) & 32.5 & 29.6 & 31.1 & \\
\hline \multicolumn{5}{|l|}{$\operatorname{Sex}(\%)$} \\
\hline Male & $15(46.9)$ & $18(56.3)$ & $33(51.6)$ & \\
\hline Female & $17(53.1)$ & $14(43.7)$ & $31(48.4)$ & \\
\hline Additional analgesics (\%) & & & & $<0.001^{*}$ \\
\hline No & $26(81.2)$ & $10(31.3)$ & $36(56.3)$ & \\
\hline Yes & $6(18.8)$ & $22(68.7)$ & $28(43.7)$ & \\
\hline Post-operative bleeding (\%) & & & & 1.000 \\
\hline No & $30(93.8)$ & $30(93.8)$ & $60(93.8)$ & \\
\hline Yes & $2(6.2)$ & $2(6.2)$ & $4(6.2)$ & \\
\hline
\end{tabular}


Table 2. Postoperative changes of VAS score

\begin{tabular}{|c|c|c|c|c|}
\hline VAS score & NSAID $(n=32)$ & $\mathrm{DW}(\mathrm{n}=32)$ & $p$ value & $p$ value $^{\dagger}$ \\
\hline Postoperative 1-day & $4.53 \pm 2.23$ & $5.81 \pm 2.32$ & 0.058 & 0.062 \\
\hline Postoperative 2-day & $5.12 \pm 2.47$ & $6.62 \pm 1.95$ & $0.009^{*}$ & $0.015^{*}$ \\
\hline Postoperative 3-day & $5.38 \pm 2.21$ & $7.47 \pm 1.68$ & $<0.001^{*}$ & $0.002 *$ \\
\hline Postoperative 4-day & $4.69 \pm 2.26$ & $8.22 \pm 1.54$ & $<0.001^{*}$ & $<0.001^{*}$ \\
\hline Postoperative 5-day & $4.44 \pm 2.15$ & $8.25 \pm 1.41$ & $<0.001^{*}$ & $<0.001^{*}$ \\
\hline Postoperative 6-day & $4.09 \pm 2.13$ & $7.62 \pm 1.39$ & $<0.001^{*}$ & $<0.001^{*}$ \\
\hline Postoperative 7-day & $3.94 \pm 2.21$ & $7.38 \pm 1.26$ & $<0.001^{*}$ & $<0.001^{*}$ \\
\hline Postoperative 8-day & $3.44 \pm 2.37$ & $6.81 \pm 1.55$ & $<0.001^{*}$ & $<0.001^{*}$ \\
\hline Postoperative 9-day & $3.12 \pm 2.49$ & $6.08 \pm 1.74$ & $<0.001^{*}$ & $0.019 *$ \\
\hline
\end{tabular}

Data are given as mean \pm standard deviations. *statistically different between NSAID group and distilled water group, which demonstrates less post-tonsillectomy pain in NSAID group, ${ }^{\dagger} p$ values were obtained after adjustment for additional analgesics. The linear regression analysis was used for the statistical adjustment. VAS: visual analogue scale, NSAID: non-steroidal anti-inflammatory drug, DW: distilled water

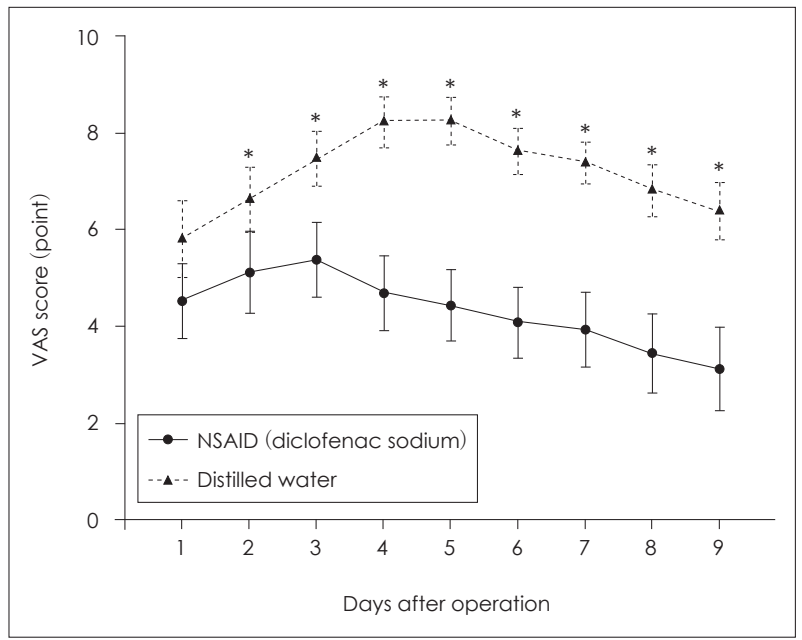

Fig. 1. Mean \pm standard error plot of postoperative VAS score per group. *statistically different between NSAID group and distilled water group. VAS: visual analog scale, NSAID: non-steroidal antiinflammatory drug.

mouthwash. Completed questionnaires were collected at the patients' first or second outpatient visit after discharge.

Statistical analyses were conducted using SPSS (version 14.0; SPSS Inc., Chicago, IL, USA) and R (version 3.1.3; The R Foundation for Statistical Computing, Vienna, Austria) software; all analyses were based on two-tailed tests. A $p$ value $<0.05$ was considered to indicate statistical significance.

\section{Results}

All patients who participated in the study completed the questionnaire. Except on POD 1, the pain level on PODs 2-9 was significantly lower in the NSAID mouthwash group than in the distilled water mouthwash group (Table 2). Five patients in the NSAID group reported scores of 9-10 on the
VAS, indicating extreme pain, compared to 21 in the control group. These pain scores were usually recorded on PODs 3-4. In the NSAID group, pain increased until POD 3 but showed a decreasing tendency from POD 4 onwards. In the distilled water group, patients reported a decrease in pain beginning on POD 5 (Fig. 1). Two patients in each group experienced minor bleeding (Table 1).

As shown in Table 1, the two groups did not significantly differ in other variables except for the use of additional analgesics, which were taken by 6 patients in the experimental group and 22 in the control group. The significant difference between the groups with respect to their VAS scores remained even after statistical adjustment for the additional medications, which is shown in the last row of Table $2(\dagger)$. The linear regression analysis was used for the statistical adjustment.

\section{Discussion}

Although tonsillectomy is one of the most commonly performed procedures among otolaryngologists, postoperative pain can lead to morbidities such as dysphagia, dehydration, and local bleeding. In addition, severe pain may extend the hospital stay. While there is no standard method to effectively control postoperative pain following tonsillectomy, among the most common methods are the use of opiates or NSAID analgesics before surgery, local anesthetics administered to the surgical site preoperatively or postoperatively, and the intravenous injection of analgesics after surgery. ${ }^{4-8)}$ The efficacy of several mouthwashes has been evaluated, but their effects on pain reduction have yet to be definitively determined. ${ }^{9,11,12)}$

Diclomed $^{\circledR}$ mouthwash is based on diclofenac sodium, a strong NSAID derived by choline diclofenac salification. 
This modification allows rapid absorption of the diclofenac in the NSAID mouthwash by the oropharyngeal mucosa and thus a reduction in inflammation and pain by inhibiting cyclooxygenase enzyme and local prostaglandin production. Analgesic effect is related to its peripheral anti-inflammatory effect and probably by weakening the pain threshold under the thalamus cortex, then the pain is decreased or interrupted. ${ }^{10)}$ This agent was also shown to inhibit the DNA synthase of Gram-positive and Gram-negative bacteria, including Pseudomonas aeruginosa and Escherichia coli. ${ }^{10,13-15)}$ In the present study, we used this NSAID mouthwash to assess the effects of NSAID mouthwash versus distilled water mouthwash in the control of pain following tonsillectomy.

The accurate absorption percentage through the mucosa and half-life of NSAID mouthwash have not been clearly defined yet. In contrast with systemic NSAID, exact measurement of these parameters would be virtually difficult in topical agent. However, more rapid onset of analgesic effect can be anticipated because of direct contact and absorption through the oropharyngeal mucosa. According to the manufacturer's pharmacokinetics, diclofenac was detectable within 10 min after contact with oral mucosa and peak concentration was reached within $45 \mathrm{~min}$, with an average maximal concentration of $21.8 \pm 5.4 \mathrm{ng} / \mathrm{mL}$. In addition, the systemic bioavailability of diclofenac solution after 7 days of mouth rinsing twice a day was $1 / 20-1 / 50$ of that obtained with oral administration of 25 mg diclofenac tablet. However, these data are not formally published.

The lack of a significant difference in the VAS scores of the two groups on POD 1, immediately after surgery, may have been related to several factors, including throat discomfort caused by endotracheal intubation and swelling of the oral cavity mucosa due to the surgical placement of a tongue retractor. On PODs 2-9, the VAS scores of the two groups differed significantly and were better in the NSAID mouthwash group.

Two patients in each group experienced a minor episode of bleeding, but it was easily controlled with ice water gargling and did not necessitate a clinical visit or emergency evaluation.

The use of additional analgesics was significantly higher in the control group. However, the significance of their VAS scores remained even after statistical adjustment for the additional medications, which was better in the experimental group. These results demonstrate that the NSAID mouthwash significantly reduced postoperative pain compared to a distilled water mouthwash even in patients taking additional analgesics.

Potential limitations of this study are relatively small number of subjects in each group and the data which are drawn only by subjective symptom scores of the patients. Postoperative use of analgesics may be another limitation. The most ideal way to evaluate the effect of NSAID mouthwash is to use the agent in the experimental group only without administration of analgesics in both groups. However, this can induce intolerable pain in the control or even in the experimental group, and patients may demand pain control. Therefore, we provided basic analgesics in both groups after operation. We excluded pediatric patients because they cannot be relied on to clearly express their degree of pain or to use a mouthwash effectively to reach the tonsillar fossa. We also did not compare the NSAID mouthwash with other agents, but in Korea there are only a few commercially available mouthwashes (e.g., chlorhexidine gluconate and hydrogen peroxide) and their main purpose is to cleanse the surgical site and prevent bacterial or fungal infection. For these reasons, we restricted our comparison of the NSAID mouthwash to distilled water mouthwash.

In conclusion, the NSAID mouthwash significantly and quickly reduced postoperative pain compared to a distilled water mouthwash, thus providing a simple and effective method to relieve post-tonsillectomy pain when used in conjunction with routine medications. The postoperative use of an NSAID mouthwash may help patients achieve an earlier return to normal daily life.

\section{Acknowledgments}

This work was supported by the Soonchunhyang University Research Fund.

\section{REFERENCES}

1) Lee SW, Kim YS, Song TH, Cha YJ, Lee BD, Chang HS. Clinical analysis of post-operative hemorrhage after tonsillectomy. Korean J Otorhinolaryngol-Head Neck Surg 1998;41(12):1590-3.

2) Sant JP. Tonsillectomy. Procedure and nursing care. AORN J 1986;44 (5):782-6.

3) Kataura A, Tsubota H. Clinical analyses of focus tonsil and related diseases in Japan. Acta Otolaryngol Suppl 1996;523:161-4.

4) Goldsher M, Podoshin L, Fradis M, Malatskey S, Gerstel R, Vaida S, et al. Effects of peritonsillar infiltration on post-tonsillectomy pain. A double-blind study. Ann Otol Rhinol Laryngol 1996;105(11):868-70.

5) Grainger J, Saravanappa N. Local anaesthetic for post-tonsillectomy pain: a systematic review and meta-analysis. Clin Otolaryngol 2008; 33(5):411-9.

6) O'Flaherty JE, Lin CX. Does ketamine or magnesium affect posttonsillectomy pain in children? Paediatr Anaesth 2003;13(5): 413-21.

7) Elhakim M, Khalafallah Z, El-Fattah HA, Farouk S, Khattab A. Ketamine reduces swallowing-evoked pain after paediatric tonsillectomy. Acta Anaesthesiol Scand 2003;47(5):604-9.

8) Salam MA, Cable HR. Post-tonsillectomy pain with diathermy and ligation techniques. A prospective randomized study in children and adults. Clin Otolaryngol Allied Sci 1992;17(6):517-9. 
9) Shin JM, Byun JY, Baek BJ, Lee JY. Effect of cold-water cooling of tonsillar fossa and pharyngeal mucosa on post-tonsillectomy pain. Am J Otolaryngol 2014;35(3):353-6.

10) Yaghini J, Abed AM, Mostafavi SA, Roshanzamir N. The effect of diclofenac mouthwash on periodontal postoperative pain. Dent Res J (Isfahan) 2011;8(3):146-9.

11) Canbay O, Celebi N, Uzun S, Sahin A, Celiker V, Aypar U. Topical ketamine and morphine for post-tonsillectomy pain. Eur J Anaesthesiol 2008;25(4):287-92.

12) Chacra ZA, Manoukian JJ, Al-Qahtani K, Al-Eisa M, Balys R, Hagr
A, et al. Hydrogen peroxide mouth rinse: an analgesic post-tonsillectomy. J Otolaryngol 2005;34(3):178-82.

13) Scholer DW, Ku EC, Boettcher I, Schweizer A. Pharmacology of diclofenac sodium. Am J Med 1986;80(4B):34-8.

14) Menassé R, Hedwall PR, Kraetz J, Pericin C, Riesterer L, Sallmann A, et al. Pharmacological properties of diclofenac sodium and its metabolites. Scand J Rheumatol Suppl 1978;(22):5-16.

15) Dastidar SG, Ganguly K, Chaudhuri K, Chakrabarty AN. The antibacterial action of diclofenac shown by inhibition of DNA synthesis. Int J Antimicrob Agents 2000;14(3):249-51. 